\title{
Association between Serum Osmolarity and Coronary Artery Stenosis Grade
}

Süleyman Ozsari* and Mehmet Ungan

Department of Family Medicine, Ankara University

Hospital, Ankara, Turkey

*Correspondling author: Dr. Süleyman Ozsari, Department of Family Medicine, Ankara University Hospital, Ankara, Turkey

Received: August 29, 2017; Accepted: September 25, 2017; Published: October 02, 2017

\begin{abstract}
Background: In our study, we investigated whether serum osmolarity, which is shaped by feeding style, is related to CAD and whether it is a reliable parameter in the progressive stages of the disease.
\end{abstract}

Methods: Our study was conducted on 399 patients with coronary angiography under elective condition with suspected CAD and 152 healthy control groups. Patients were divided into three groups using Gensini Score. Patient and control group were compared in terms of Osmolarity (calculated), sodium, BUN

Results: The data obtained from routine blood measurements before coronary angiography the mean osmolarity was calculated as $293.34 \pm 4.39 \mathrm{mOsm} / \mathrm{L}$. In the control group, mean osmolarity were calculated as $291.81 \pm 4.00 \mathrm{mOsm} / \mathrm{L}$. As a result of analysis between patient and control group, there was a significant difference between sodium, BUN and calculated osmolarity $(p<0.05)$. There was no significant difference in the osmolarity values among the GENSINI score groups ( $p$ : 0.025).

Conclusion: The calculation of osmolarity can be recorded in long-term follow-ups and used as a risk assessment until symptoms occur during the development of CAD. Thus, the arrangements regarding the feeding of the individuals can be based on concrete data and more effective interventions can be made. Once the diagnosis of CAD is established, osmolarity is not a measurement that can be used following the disease.

Keywords: Serum Osmolarity; Coronary Artery Stenosis; Long term followup; Family Medicine

\section{Introduction}

According to the death statistics of the Turkish Statistical Institute (TURKSTAT), it seems that there is a tendency to increase in the total number of deaths together with the fact that heart diseases maintain their proportion over the years [1]. The positive aspect of cardiovascular diseases is that they are "preventable" to a large extent. The most prevalent stages and risk factors are the effects on the formation of atherosclerosis.

Serum osmolarity measurement is an easy and noninvasive method that is easily calculated in primary care centers and family health centers. Normal value is $280-295 \mathrm{mOsm} / \mathrm{kg} \mathrm{H}_{2} \mathrm{O}$ and this value is measured by osmometer. But with the formula, it can be calculated very close to normal:

Osmolality $\left(\mathrm{mOsm} / \mathrm{kg} \mathrm{H}_{2} \mathrm{O}\right)=2[\mathrm{Na}+]+$ Glucose $/ 18+\mathrm{BUN} /$ $2.8 "[2]$

It has been suggested that consumption of osmotic burdenincreasing nutrients induces atherosclerotic process by increasing body temperature [3].

There are several studies showing that there is a significant correlation between coronary artery disease and measurable and computable osmolality [2]. In this study; Which is one of the goals of planning in the short term as part of the fight against cardiovascular diseases, which is considered as the most important cause of mortality in our country; "To work to increase the awareness of cardiovascular diseases and risk factors in the community to reduce the risk of developing these diseases " and " to gain nutrition habits that reduce the risks of collecting cardiovascular diseases" [4]; In this context, to put forward the parameters leading to preventable causes at an early stage.

\section{Methods}

In our study, 399 patients who underwent elective coronary angiography were included in the Cardiology Clinic of Ankara University between 01 March 2016 and 31 August 2016. Between the same dates, 152 healthy control groups who applied to the Ankara University Family Medicine clinic were included in the study. Patients who agreed to participate in the study was signed consent forms. When the patient sample was constructed, according to the results of angiography, patients were divided into 3 groups by using GENSINI score in terms of the presence and severity of CAD. A total of 118 patients with a total score of 0,123 patients with score scores $1-19$, and 158 with a score of 20 and over were included in the study. Patients with known glucose metabolism disorders (anamnesis, clinical diagnosis, chronic illness report), patients with blood glucose level (FPG $>110 \mathrm{mg} / \mathrm{dl})$ measured before or during the last month, patients with apparent renal insufficiency (GFH $\leq 60 \mathrm{ML} / \mathrm{min} /$ 
Table 1: Patient's Laboratory Parameters and Computable Mean Osmolarity.

\begin{tabular}{|c|c|c|c|}
\hline & Mean & Min & Max \\
\hline Sodium $(\mathrm{mEq} / \mathrm{mL})$ & $141.42 \pm 2.12$ & 133 & 147 \\
\hline BUN $(\mathrm{mg} / \mathrm{dL})$ & $15.35 \pm 4.03$ & 7 & 31 \\
\hline Glucose $(\mathrm{mg} / \mathrm{dL})$ & $90.39 \pm 9.18$ & 62 & 110 \\
\hline Osmolarity $(\mathrm{mOsm} / \mathrm{L})$ & $293.34 \pm 4.39$ & 276.37 & 306.8 \\
\hline
\end{tabular}

Table 2: Control Group's Laboratory Parameters and Computable Mean Osmolarity.

\begin{tabular}{|c|c|c|c|}
\hline & Mean & Min & Max \\
\hline Sodium $(\mathrm{mEq} / \mathrm{mL})$ & $141.00 \pm 1.83$ & 136 & 144 \\
\hline BUN $(\mathrm{mg} / \mathrm{dL})$ & $13.00 \pm 3.12$ & 6 & 20 \\
\hline Glucose $(\mathrm{mg} / \mathrm{dL})$ & $89.00 \pm 7.96$ & 68 & 110 \\
\hline Osmolarity $(\mathrm{mOsm} / \mathrm{L})$ & $291.81 \pm 4.00$ & 278.87 & 298.87 \\
\hline
\end{tabular}

$1.73 \mathrm{~m}^{2}$ ), patients with mental or cognitive impairment, those who had received alcohol within the last 24 hours, and those who did not want to participate in the study were not included in the study.

\section{Statistical analyses}

Analysis of the data was done in SPSS 15 package program. Descriptive statistics are shown as median (min-max) for variables with normal distribution, nominal variables as number of cases and (\%). Statistical significance was investigated with the T-test for the averages between the groups and the Mann-Whitney $U$ test for the median values. If the number of groups is more than twice in the subsequent evaluation; Statistical significance was investigated by Kruskal Wallis test for the mean between groups. Nominal variables were assessed by Pearson Chi-Square or F exact test. A multivariate logistic regression analysis was performed to determine independent risk factors for coronary artery disease. In logistic regression analysis, risk parameters and confidence interval were determined by taking parameters affecting as a result of univariate analysis. $\mathrm{P}$ value lower than 0.05 is considered as statistically significant.

\section{Results}

The study included 399 patients who applied to cardiology clinic and underwent elective coronary angiography. The mean age of the patients was $60.51 \pm 11.09$ years $(22-89), 67.2 \%(n=268)$ of these patients were male and $32.8 \%(\mathrm{n}=131)$ of these patients were female. Between the same dates, family medicine clinic; 152 patients with no clinical signs and symptoms of cardiovascular disease and no diagnosis were taken as a control group. While the mean age of the control group was $54.57 \pm 11.42(20-88), 33.6 \%(n=51)$ were male and $66.4 \%(\mathrm{n}=101)$ were female.

The mean values of sodium levels of the patients from routine blood measurements before coronary angiography were $141.42 \pm$ $2.12 \mathrm{mEq} / \mathrm{mL}$, mean BUN value was $15.35 \pm 4.03 \mathrm{mg} / \mathrm{dL}$, blood sugar value was $90.39 \pm 9.18 \mathrm{mg} / \mathrm{dL}$. The mean osmolarity calculated from these parameters was calculated as $293.34 \pm 4.39(\mathrm{mOsm} / \mathrm{L})($ Table 1$)$.

The control group, mean sodium level was $141.00 \pm 1.83 \mathrm{mEq} / \mathrm{mL}$, mean BUN level was $13.00 \pm 3.12 \mathrm{mg} / \mathrm{dL}$ and mean blood glucose level was $89.00 \pm 7.96 \mathrm{mg} / \mathrm{dL}$. The mean osmolarity calculated from these parameters was found to be $291.81 \pm 4.00 \mathrm{mOsm} / \mathrm{L}$ (Table 2).
Table 3: Grouping of patients according to GENSINI Score.

\begin{tabular}{|c|c|c|}
\hline & Frequency & Percent (\%) \\
\hline 0 & 118 & 29.6 \\
\hline $1-19$ & 123 & 30.8 \\
\hline$\geq 20$ & 158 & 39.6 \\
\hline Total & 399 & 100 \\
\hline
\end{tabular}

Table 4: Osmolarity Levels of Patients by GENSINI Score Group.

\begin{tabular}{|c|c|c|c|c|}
\hline GENSINI & Patient & Mean \pm St.D. & Min & Max \\
\hline 0 & 118 & $293.71 \pm 4.56$ & 278.26 & 304.61 \\
\hline $1-19$ & 123 & $293.58 \pm 4.51$ & 276.37 & 305.50 \\
\hline$\geq 20$ & 158 & $292.87 \pm 4.15$ & 278.93 & 306.80 \\
\hline Total & 399 & $293.34 \pm 4.39$ & 276.37 & 306.80 \\
\hline
\end{tabular}

Statistical analysis of Mann-Whitney U and Wilcoxon W between the patient controls revealed no significant difference between sodium, BUN and calculated osmolarity $(\mathrm{p}<0.05)$, and this difference was not significant between the blood sugars $(\mathrm{p}=0.73)$.

Patient group; 3 groups were separated using GENSINI scoring. 118 patients with score "0", 123 patients with score 1-19, and 158 patients with score 20 and over were selected (Table 3 ).

The mean serum osmolarity of the group with a total score of 0 was $293.71 \pm 4.56 \mathrm{mOsm} / \mathrm{l}$, the mean serum osmolarity of the group with a score of $1-19$ was $293.58 \pm 4.51 \mathrm{mOsm} / 1$, the score was 20 and above the mean serum osmolarity was measured as $292.87 \pm$ $4.15 \mathrm{mOsm} / \mathrm{lt}$ (Table 4).

There was no significant difference in the osmolarity levels among the GENSINI score groups $(\mathrm{p}=0.225)$. There was no significant difference between the osmolarity levels of the patient group with GENSINI score "0" $(293.71 \pm 4.56 \mathrm{mOsm} / \mathrm{lt})$ and the group with GENSINI score $>1(293.19 \pm 4.32 \mathrm{mOsm} / \mathrm{lt})(\mathrm{p}=0.280)$. When the relationship between the laboratory parameters of the patient group and the GENSINI scores is examined, there was a significant difference with sodium but not with other parameters (Table 5).

\section{Discussion}

Among the deaths due to noncommunicable diseases in the world, deaths due to ischemic heart diseases are the highest (\%12.6). However, deaths due to cardiovascular diseases (CVD) are expected to protect the first order for many years. However, in recent years, especially in developed countries, increasing importance of preventive health services and increased awareness of public health have led to a decrease in mortality due to CVD and a tendency to increase this rate in developing countries [5].

Our study; It is aimed to increase the awareness of the individuals at risk especially in the scope of preventive medicine and to increase the reliability level of the obtained data with wide field studies in order to increase the awareness of the individuals at risk and to obtain the concrete data which can be easily obtained in terms of cost and applicability in primary care physicians.

Nutrition with high osmolarity burden leads to increased temperature in the body, increases damage to the veins, and leads to lipid accumulation resulting in the formation of atherosclerosis [6]. 
This emphasizes the importance of parameters that create osmolar loads such as glucose, sodium and protein in the diet as well as genetic and environmental factors in the emergence of CVD. Several studies have investigated the effect of sodium on CVDs $[7,8]$.

The fact that dietary high sodium intake plays a triggering role on heart disease suggests that the most important lifestyle change is the restriction of salt intake on the diet and its transformation into a general health policy [8]. In many developed countries, the daily limits of sodium intake are determined by relevant health organizations and it is suggested that they should not be exceeded. In a meta-analysis conducted by the American Heart Association in 2012, studies involving many animal and human experiments have been proposed to increase structural and functional impairment in excess sodium, heart, and large vessels and kidneys and emphasize the need to promote sodium intake below the daily recommended amount to protect the population from cardiovascular disease $[9,10]$.

In a recent meta-analysis, although the effects of sodium intake on cardiovascular mortality in the global sense are uncertain, high sodium intake has been shown to increase blood pressure and constitute a risk factor for cardiovascular disease [11]. As a result of these evaluations, the sodium height needs to be considered in every age group. In our study, the sodium levels of 551 people were compared, including 152 controls and 399 patient groups. A significant increase was found between the control group and the patient group with increasing osmolarity levels and sodium levels. However, there was no correlation between the severity of the stenosis and the height of the sodium in the patient group.

However, in recent years; many studies have been carried out to demonstrate the applicability of simple and detectable high laboratory values to CAD that can be used at a lower cost and wider physician domain. In a meta-analysis involving 40 studies published in the International Journal of Cardiology in 2014, high mean platelet volume was associated with coronary artery disease. This high value has been concluded by combining $\mathrm{CAH}$ with other risk factors, which may be useful in developing a risk prediction model [12].

In a study comparing 193 patients with coronary angiography results and blood group values before angiography, the distribution of red cell distribution was significantly higher in patients with CAD compared to those without CAD. Thus, the extent of red cell distribution was regarded as a readily accessible laboratory value associated with the presence of CAD [13]. The study we conducted showed that a meaningful difference between the computable osmolarity value of individuals with CAD and the healthy population could be regarded as a laboratory value that could be used to assess risk of CAD in the first step.

In a study conducted by Arbel et al. In 2012, it was found that there was a correlation between high neutrophil/lymphocyte ratio (above 3) calculated from the data obtained from the laboratory results and coronary angiography resultant CAD severity, and this ratio was found to be higher for risky individuals It can be used as a marker [14]. Although there was a significant difference between the calculated osmolarity values of individuals with CAD and those of healthy individuals, there was no significant between osmolarity and severity of stenosis in our evaluation of GENSINI score in individuals with CAD. As a result, the calculated osmolarity did not correlate with the severity of CAD such as neutrophil/lymphocyte ratio, and it would not be meaningful in the future.

In this study, hyperosmolarity has been shown to increase cardiovascular mortality risk by 4.3 -fold and a 3.9-fold increase in the risk of cardiovascular mortality even after mid-term monitoring [15].

These studies reveal the relationship between osmolarity and mortality after development of CAD. It is likely that this relationship is the result of multiple organ failure resulting from the course of the present disease. However, it is not known how long this insufficiency caused the osmolarity to rise before the onset of the symptoms and clinical condition of the disease.

In 2015, Hakan Demirci et al. osmolarity is one of the important studies that revealed the relationship of CAD. 141 cases were included in this study. There are 61 stories of episodes in the cases. The case group of patients with CAD history was divided into two groups, the remaining 80 patients were control group. A significant difference was found between the control and the patient group in terms of plasma osmolarity values as in our study. The disadvantage of not using measurable osmolality in place of the computable osmolarity mentioned in this study. However, it has also been reported that osmolarity values calculated in the absence of ethanol or toxins are similar to measurable osmolality values [16]. In our study, some of the reasons that could cause osmolar gap were excluded and this situation was tried to be reduced.

Plasma glucose, BUN and sodium; Are the main constituents of plasma osmolarities. Computable osmolarity, including these components, is an important indicator for CAD and mortality [17] Hyperosmolar nutrition, termed sodium, glucose and protein-rich nutrition, is the basis for atherosclerosis, leading to metabolic activity resulting in increased heat, especially coronary artery deterioration in the body6. It is important to remove the person's hyperosmolar from the diet or to define the limits, to protect from the CAD, at least to delay disease development.

Osmolarity has an important place in the course of many systemic diseases, especially in CAD. In terms of preventive medicine, which is one of the most important pillars of family medicine and primary care, it is one of our important aims to reveal the awareness of the risky population and to take concrete precautions.

\section{Conclusion}

The results of our study showed that there is a statistically significant difference in osmolarity between the patient group and the control group. Although the value of osmolarity in the sense of preventive medicine is no longer important after the clinical development of CAD, it can be used in following a healthy individual. Computable osmolarity is an easy and inexpensive method to look at because it contains the parameters that the physician can reach with blood tests.

It has a greater importance to prevent disease than to treat. In this respect, the introduction of new parameters for this purpose; the development of easy, inexpensive and accessible methods is important in terms of reaching more individuals and there is a need to work more in this direction. 


\section{References}

1. Institute Ts. Death Statistics, 2014.

2. Gotto Jr A. Risk factors for coronary artery disease. Heart disease: a textbook of cardiovascular medicine. 1992.

3. Mathur R. The role of hyperosmolal food in the development of atherosclerosis Medical hypotheses. 2005; 64: 579-581.

4. Turkey Cardiovascular Disease Prevention and Control Program 2015-2020 2015.

5. Health in 2015: From Millennium Development Goal to Sustainable Development Goals. 2016.

6. Mathur RK. Role of diabetes, hypertension, and cigarette smoking on atherosclerosis. Journal of cardiovascular disease research. 2010; 1: 64-68.

7. Cook NR, Cohen J, Hebert PR, Taylor JO, Hennekens CH. Implications of small reductions in diastolic blood pressure for primary prevention. Archives of Internal Medicine. 1995; 155: 701-709.

8. He J, Ogden LG, Bazzano LA, Vupputuri S, Loria C, Whelton PK. Dietary sodium intake and incidence of congestive heart failure in overweight US men and women: first National Health and Nutrition Examination Survey Epidemiologic Follow-up Study. Archives of internal medicine. 2002; 162: 1619-1624.

9. Whelton PK, Appel LJ, Sacco RL, et al. Sodium, blood pressure, and cardiovascular disease. Circulation. 2012; 126: 2880-2889.

10. Bertram Y, Steyn K, Wentze-Viljoen E, Tollman S, Hofman J. Reducing the sodium content of high-salt foods: effect on cardiovascular disease in South Africa. SAMJ: South African Medical Journal. 2012; 102: 743-745.
11. Mozaffarian D, Fahimi S, Singh GM, et al. Global sodium consumption and death from cardiovascular causes. New England Journal of Medicine. 2014; 371: 624-634.

12. Sansanayudh N, Anothaisintawee T, Muntham D, McEvoy M, Attia J. Mean platelet volume and coronary artery disease: a systematic review and metaanalysis. International journal of cardiology. 2014; 175: 433-440.

13. Isik $\mathrm{T}$, Uyarel $\mathrm{H}$, Tanboga $\mathrm{IH}$, et al. Relation of red cell distribution width with the presence, severity, and complexity of coronary artery disease. Coronary artery disease. 2012; 23: 51-56.

14. Arbel $Y$, Finkelstein A, Halkin A, et al. Neutrophil/lymphocyte ratio is related to the severity of coronary artery disease and clinical outcome in patients undergoing angiography. Atherosclerosis. 2012; 225: 456-460.

15. Figuero SB, Jiménez-Mena M, Marcos JO, et al. Dehydration and serum hyperosmolarity as new predictors of mortality after acute coronary syndrome. International journal of cardiology. 2014; 172: e472-e474.

16. Fauci AS. Harrison's principles of internal medicine. Vol 2: McGraw-Hill, Medical Publishing Division New York; 2008.

17. Rohla M, Freynhofer MK, Tentzeris I, et al. Plasma osmolality predicts clinical outcome in patients with acute coronary syndrome undergoing percutaneous coronary intervention. European Heart Journal: Acute Cardiovascular Care. 2014; 3: 84-92.
J Fam Med - Volume 4 Issue 6 - 2017

ISSN : 2380-0658 | www.austinpublishing group.com

Ozsari et al. (C) All rights are reserved
Citation: Ozsari S and Ungan M. Association between Serum Osmolarity and Coronary Artery Stenosis Grade. J Fam Med. 2017; 4(6): 1128 